\title{
Bombyx mori gloverin A2 alleviates enterotoxigenic Escherichia coli-induced inflammation and intestinal mucosa disruption
}

Qian Lin ${ }^{1,2}$, Guoqi Su ${ }^{1,2}$, Aimin Wu ${ }^{3}$, Daiwen Chen ${ }^{1,2}$, Bing Yu ${ }^{1,2}$, Zhiqing Huang ${ }^{1,2}$, Yuheng Luo ${ }^{1,2}$, Xiangbing Mao ${ }^{1,2}$, Ping Zheng ${ }^{1,2}$, Jie $\mathrm{Yu}^{1,2}$, Junqiu Luo ${ }^{1,2}$ and Jun $\mathrm{He}^{1,2^{*}}$ (D)

\begin{abstract}
Background: Enterotoxigenic Escherichia coli (ETEC) is one of the leading bacterial causes of intestinal inflammation and diarrhea. However, the ETEC is frequently resistant to common antibiotics. In this study, we explored the role of a novel antibacterial peptide Bombyx mori gloverin A2 (BMGlvA2) in alleviating ETEC-induced inflammation and intestinal epithelium disruption in mice.

Methods: An ETEC-challenged mice model was used, and the ETEC-challenged mice and non-challenged mice were treated by the BMGIvA2 at different doses.

Results: ETEC challenge not only elevated the concentrations of serum inflammatory cytokines such as the IL-6 and TNF-a $(P<0.01)$, but also elevated the concentrations of serum creatinine and urea $(P<0.05)$. However, BMGlvA2 attenuated the inflammatory responses by decreasing the serum inflammatory cytokines and improving the metabolisms in ETEC-challenged mice, and alleviated the ETEC-induced tissue damage in spleen. Moreover, BMGlvA2 treatment significantly elevated the duodenum villus height and decreased the crypt depth in the duodenum and ileum in ETEC-challenged mice $(P<0.05)$. Interestingly, BMGlvA2 improved the distribution and abundance of tightjunction protein ZO1 in duodenum and ileum epithelium after ETEC-challenge. Moreover, BMGlvA2 significantly downregulated the expression levels of inflammatory cytokines (IL-1 $\beta, I L-6$, and TNF- $a$ ) and the apoptosis-related genes (Caspase 8 and Caspase 9) in jejunal mucosa $(P<0.05)$ in the TETC-challenged mice. Importantly, BMGlvA2 significantly elevated the expression levels of critical genes related to mucosal barrier functions such as the mucins (MUC1 and MUC2) and glucose transporter (GLUT2) in the intestinal mucosa $(P<0.05)$.
\end{abstract}

Conclusion: Our results suggested a novel function of the conventional antibacterial peptides, and the anti-bacterial and anti-inflammatory properties of BMGlvA2 may allow it a potential substitute for conventionally used antibiotics or drugs.

Keywords: BMGlvA2, E. coli K88, Mice, Inflammation, Intestinal mucosa

\footnotetext{
*Correspondence: hejun8067@163.com

${ }^{1}$ Institute of Animal Nutrition, Sichuan Agricultural University, Chengdu,

Sichuan 611130, People's Republic of China

${ }^{2}$ Key Laboratory for Animal Disease-Resistance Nutrition and Feed, Ministry of

Agriculture, Chengdu, Sichuan 625014, People's Republic of China

Full list of author information is available at the end of the article
}

(c) The Author(s). 2019 Open Access This article is distributed under the terms of the Creative Commons Attribution 4.0 International License (http://creativecommons.org/licenses/by/4.0/), which permits unrestricted use, distribution, and reproduction in any medium, provided you give appropriate credit to the original author(s) and the source, provide a link to the Creative Commons license, and indicate if changes were made. The Creative Commons Public Domain Dedication waiver (http://creativecommons.org/publicdomain/zero/1.0/) applies to the data made available in this article, unless otherwise stated. 


\section{Background}

Animal diseases caused by enterotoxigenic Escherichia coli (ETEC) infection typically appear as severe diarrhea and rapid dehydration. Human and mammlian animals such as the mice and pigs are susceptible to ETEC $[1,2]$. ETEC adhere to the small intestinal microvilli, which induces morphological lesions and produce enterotoxins acting locally on enterocytes [3]. Previous studies indicated that endotoxins usually caused intestinal mucosa inflammation and destruction of tight junction integrity and epithelial cell apoptosis [4], which subsequently led to disruption of intestinal homeostasis and damage of the intestinal barrier functions. Currently, antibiotics and other chemical drugs have been widely used to treat the ETEC infection. However, long-term or high-dose treatments of antibiotics not only lead to drug resistance, but also lead to their residues in animal product. For instance, polypeptides (colistin), aminoglycosides (gentamicin, streptomycin) and tetracyclines (Doxycycline) are generally prescribed for infections caused by gram-negative bacteria [5-8]. However, these drugs may cause various Adverse Drug Reactions (ADRs), such as allergy, diarrhea, nausea and hypopsia etc. $[9,10]$. Therefore, substitute for conventionally used antibiotics has attracted considerable research interest worldwide.

The antimicrobial peptides (AMPs) are a group of immune-related peptides/ proteins that protect the host from microbial infections [11-13]. Antimicrobial peptides exhibit extensive activity against gram-positive and gramnegative bacteria, yeasts, and fungi [14]. Especially, they exhibit activity against some antibiotics-resistant bacterial species. For instance, the tridecaptin $\mathrm{M}$ was found to exhibit activity against many colistin-resistant $E$. coli strains in vitro and in vivo [15]. Importantly, a number of studies have shown that AMPs plays a critical role in immune regulation $[16,17]$. For instance, the AMPs were found to regulate the secretion of inflammatory cytokines in a variety of animal species $[18,19]$. In the last decades, a number of AMPs such as the ceropins, histatins, defensins, and cathlicidins have been isolated from various animals or microbial species [20,21]. BMGlvA2 is an induced antimicrobial insect protein isolated from Bombyx mori (B. mori), which is a small cationic linear $\alpha$-helical peptide belonging to cecropin family [22]. BMGlvA2 was found to inhibit the growth of bacteria by binding to the lipopolysaccharide (LPS) components existing on the surface of bacterial membrane, which increases the permeability of the membrane. However, it has no toxic effects on mammalian cells [22]. Although evidences are accumulating to show that the AMPs can serve as a critical regulator for diverse biological events including immune responses [23-26], the involvement of BMGlvA2 in regulating the ETEC-induced inflammation and intestinal disruption is just beginning to be explored.

In our previous study, the BMGlvA2 was successfully expressed and purified by using a heterologous system, and the recombinant BMGlvA2 was found to show a moderate antibacterial activity against the ETEC [27]. In this study, we explored the role of the BMGlvA2 in alleviating ETECinduced inflammation and intestinal epithelium disruption in mice. Our result offers novel insights into the role of the AMPs and will also facilitate the development of novel substitute for conventionally used antibiotics or drugs.

\section{Methods}

\section{Preparation of BMGlvA2}

The engineered strain L Orgami B (DE3)-harboring the recombinant plasmid (pet32a-gloverin A2) was previously constructed in our laboratory [27]. The protein expression was induced by $1.0 \mathrm{mM}$ isopropyl $\beta-\mathrm{d}-1$ thiogalactoside (IPTG). After incubation for $8 \mathrm{~h}$ at $28^{\circ} \mathrm{C}$, bacterial cells were harvested by centrifugation at $8000 \mathrm{r} / \mathrm{min}$ for $15 \mathrm{~min}$ at $4{ }^{\circ} \mathrm{C}$, $20 \mathrm{~mL}$ phosphate buffer solution (PBS) was added to washing the precipitation, centrifuged at $8000 \mathrm{r} / \mathrm{min}$ for $15 \mathrm{~min}$ at $4 \mathrm{C}$, and the supernatant was discarded. Then $20 \mathrm{ml}$ lysis buffer was added and incubated at $4{ }^{\circ} \mathrm{C}$ for the overnight. Then, schizolytic cells were sonicated (4s pulse and $8 \mathrm{~s}$ interval; 30 cycles; Sonics-Vibra cell, USA). The supernatant was harvested by centrifugation at $8000 \mathrm{r} / \mathrm{min}$ for $20 \mathrm{~min}$ at $4{ }^{\circ} \mathrm{C}$. The supernatant obtained above was filtered by $0.22 \mu \mathrm{m}$ filter, and then applied to $\mathrm{Ni} 2^{+}$- IDA column (Sangon Biotech, China) and purified according specification. Protein concentration was quantified by the BCA assay (Beyotime, China).

\section{Animal trial}

The experimental procedure and animal care were carried out in compliance with the regulations of the Animal Care Committee of Sichuan Agricultural University (No. 20180701). Sixty male ICR (Institute of Cancer Research) mice (4 weeks) were purchased from the Da Shuo laboratory animal Co., Ltd. (Chengdu, China). A 2 (sterile saline or E. coli K88 challenge) $\times 3$ (three BMGLvA2 doses) factor design was used and mice were randomly divided into 6 treatments according to the principle of similar body weight $(n=10)$. All mice were housed at single cage at a constant humidity $(40-70 \%)$ and temperature $\left(20-25^{\circ} \mathrm{C}\right)$ under a 12 $\mathrm{h}$ light/dark cycle with free access to water and feed. The injections of BMGlvA2 $(0,4,8 \mathrm{mg} / \mathrm{kg})$ were carried out for 6 days (once a day) via $1 \mathrm{ml}$ insulin syringe (Braun, Melsungen, Germany). At $7 \mathrm{~d}$, mice were either challenged (intraperitoneal injection) by $200 \mu \mathrm{l}$ sterile saline or E. coli K88 culture solution $\left(\mathrm{OD}_{600}=0.5\right)$. Five hours after challenge, the mice were anesthetized via 20-s exposure to carbon dioxide and subjected to collect the blood samples by cardiac puncture [28]. Duodenum, jejunum and ileum samples were taken immediately after cervical dislocation. A portion of the sample was fixed in formaldehyde solution for morphological observation and the other portion was rapidly frozen in liquid nitrogen and stored at $-80^{\circ} \mathrm{C}$ until 
analysis. Blood samples were centrifuged at $3000 \times \mathrm{g}$ for 15 min at $4{ }^{\circ} \mathrm{C}$, after which the serum was separated and stored at $-20^{\circ} \mathrm{C}$ for further analysis.

\section{Cytokine measurements}

IL-1 $\beta$, IL-6 and TNF- $\alpha$ (Beijing Sizhengbai Biotech, China), D-Lactic acid (Beijingchenglin Biotech, China) were determined by enzyme-linked immunosorbent assay (ELISA), using commercial kits according to the manufacturer's recommendations. Albumin (ALB), total protein (TP), Urea, creatinine (CRE), c-reactive protein (CRP), aspartate transaminase (AST) and alanine aminotransferase (ALT) were detected by The 3100 type automatic biochemical analyzer (Hitachi, Tokyo, Japan), and globulin (GLB) were calculated based on TP and ALB.

\section{Histopathological assays}

Histological analysis was performed on duodenum, jejunum, ileum, and spleen. The samples were fixed overnight in $4 \%$ paraformaldehyde and then dehydrated with different concentrations of ethanol. After dehydration, samples were embedded in paraffin and were subsequently cut into $4-\mu \mathrm{m}$ thick sections. The prepared tissue sections were stained with hematoxylin and eosin (H\&E) and sealed with a neutral gum. The image of spleen tissue sections was analyzed by using the Image-pro Plus 6.0 (Media Cybernetics, USA), and the intestinal villus height and crypt depth were measured by using an image processing and analysis system (Image-Pro Plus 6.0, Media Cybernetics, Inc., Bethesda, MD, USA).

\section{Immunofluorescence staining}

The jejunal tissue section was deparaffinized and rinsed with distilled water for $5 \mathrm{~min}$. Tissue sections were then subjected to antigen retrieval by ethylenediaminetetraacetic acid (EDTA, 1 mol/L, pH 9.0, Gooddbio Technology Co., Ltd., Wuhan, China). Before overnight incubating at $4{ }^{\circ} \mathrm{C}$ with rabbit anti-ZO-1 polyclonal antibody (Gooddbio Technology Co., Ltd., Wuhan, China), sections were blocked with $3 \%$ bovine serum albumin. The sections were washed three times with PBS ( $\mathrm{pH}$ 7.4) for 5 min each time, and then goat anti-rabbit IgG-FITC secondary antibody (Gooddbio Technology Co., Ltd., Wuhan, China) was added thereto, followed by incubation at room temperature for $50 \mathrm{~min}$ in the dark. 4',6-diamidino-2-phenylindole (DAPI, Gooddbio Technology Co., Ltd., Wuhan, China) stain was added to incubated for $10 \mathrm{~min}$ at room temperature after tissue sections were washed with PBS $(\mathrm{pH}=7.4)$. Finally, the fluorescence of the sections was visualized by a confocal scanning microscope (NIKON ECLIPSE TI-SR), and the images were taken using NIKON DS-U3 software.

\section{RNA isolation and quantitative RT-PCR}

Total RNA was extracted from jejunal samples using TRIzol Reagent (TaKaRa, Dalian, China). Then, each RNA sample was reverse-transcribed into cDNA using reverse transcriptase (Takara, Tokyo, Japan) after detection of RNA concentration and purity by spectrophotometer (Beckman Coulter, DU800). The PCR primer sequences were designed using Primer Premier 5.0 and are listed in Additional file 1: Table S1. Briefly, quantitative PCR was performed by QuanStudio 6 Flex Real-Time PCR detection system (Applied Biosystems, Foster City, CA, USA) with a total of $10 \mu \mathrm{L}$ of assay solution containing $5 \mu \mathrm{L}$ SYBR Green mix (Takara), $0.2 \mu \mathrm{L}$ Rox, $3 \mu \mathrm{L}$ deionized $\mathrm{H} 2 \mathrm{O}, 1 \mu \mathrm{L}$ cDNA template, and $0.4 \mu \mathrm{L}$ each of forward and reverse primers. The comparative $\mathrm{Ct}$ value method was used to quantify mRNA expression relative to $\beta$-actin expression.

\section{Statistics analysis}

All statistical analysis was performed using SPSS 21.0 software. The individual mouse was used as the experimental unit, and all data were expressed as mean \pm standard error (SEM). Statistical analysis was carried out using two-way ANOVA followed by Duncan's multiple comparisons test. Image production using GraphPad Prism software (Version 7. GraphPad Software Inc., CA, USA).

\section{Results}

Effect of BMGlvA2 on fecal score and integrity of immune organ

In this study, the BMGlvA2 has been successfully expressed and purified (Additional file 1: Figure S1). Mice were challenged either with saline or ETEC after treated the purified BMGlvA2. The fecal score was analyzed by Disease activity index (DAI) [29]. We found that ETEC challenge significantly increased the fecal score. However, BMGLlvA2 injection decreased the fecal score in the ETEC-challenged mice (Table.1). Interestingly, histopathological assays showed that the spleen exhibited mild focal degeneration, necrosis, and expansion of splenic nodules in the white pulp area in the ETECchallenged mice (mice in the same group showed the same trend). However, BMGLlvA2 attenuated the ETEC-induced tissue damage in the spleen (Fig. 1).

\section{Effect of BMGlvA2 on serum inflammatory cytokines and metabolic indicators}

Some of the critical inflammatory cytokines and metabolic indicators in serum were investigated. As shown in Table 2, the serum concentrations of Urea, CREA, IL- 6 , and TNF- $\alpha$ were significantly increased in the mice upon ETEC challenge $(P<0.05)$. While the concentrations of globulin, albumin, and total protein were significantly decreased in the ETEC-challenged mice $(P<0.05)$. Interestingly, BMGlvA2 significantly reduced the serum concentrations of 
Table 1 Effect of BMGlvA2 on fecal score of the mice

\begin{tabular}{|c|c|c|c|c|c|c|c|c|}
\hline$-K 88$ & & & $+K 88$ & & & $P$ value & & \\
\hline $0.0 \mathrm{mg} / \mathrm{kg}$ & $4.0 \mathrm{mg} / \mathrm{kg}$ & $8.0 \mathrm{mg} / \mathrm{kg}$ & $0.0 \mathrm{mg} / \mathrm{kg}$ & $4.0 \mathrm{mg} / \mathrm{kg}$ & $8.0 \mathrm{mg} / \mathrm{kg}$ & Interaction & K88 & $A$ \\
\hline $0.00 \pm 0.00^{b}$ & $0.00 \pm 0.00^{b}$ & $0.40 \pm 0.08^{\mathrm{ab}}$ & $1.30 \pm 0.16^{\mathrm{a}}$ & $0.30 \pm 0.10^{\mathrm{ab}}$ & $0.50 \pm 0.09^{\mathrm{ab}}$ & 0.094 & 0.020 & 0.229 \\
\hline
\end{tabular}

The data were expressed as mean \pm SEM. Fecal fraction of mice within $5 \mathrm{~h}$ after injection of $E$. coli K88 or LB medium. The fecal score was analyzed by Disease activity index (DAl). Data with different superscript letters in a row indicated that the differences between different treatment groups were statistically significant $(p<0.05)$

inflammatory cytokines such as the IL-6, and TNF- $\alpha(P<$ $0.05)$. Moreover, the serum concentrations of UREA and CREA were decreased in the ETEC-challenged mice upon BMGlvA2 treatment $(P<0.05)$.

\section{Effect of BMGlvA2 on intestinal morphology and the distribution of zonula occludens- 1 proteins}

Histopathological assays indicated that ETEC-challenge impaired the intestinal mucosa, which has been evidenced by shortened villi, necrosis, and loss of epithelial cells in the intestinal epithelium (Fig. 2). After quantitative analysis, we found that ETEC-challenge significantly decreased the villus height in the duodenum and jejunum $(P<0.05)$. Moreover, ETEC-challenge significantly increased the crypt depth and decreased the ratio of villus height to crypt depth $(\mathrm{V} / \mathrm{C})$ in the ileum (Table 3). However, BMGlvA2 treatment at a high dose $(8 \mathrm{mg} / \mathrm{kg})$ attenuated the ETEC-induced mucosa lesion. The villus height of duodenum in the BMGlvA2treated mice $(8 \mathrm{mg} / \mathrm{kg})$ was higher than the ETEC- challenged mice $(P<0.05)$. Moreover, BMGlvA2 treatments at a higher dose $(8 \mathrm{mg} / \mathrm{kg})$ decreased the crypt depth both in the duodenum and ileum $(P<0.05)$. Additionally, we explored the distribution and abundance of zonula occludens-1 (ZO-1), one of the major tight-junction-related proteins located in the intestinal epithelium, by immunofluorescence analysis. We found that the ZO-1 staining in the jejunum was diffuse with little staining at the intercellular tight junction region in the ETEC-challenged mice, indicating disruption of the tight junction upon ETEC infection (mice in the same group showed the same trend). However, BMGlvA2 treatment attenuated the ETEC-induced disruption by improving the localization and abundance of the ZO1 proteins in the intestinal epithelium (Fig. 3).

\section{Effect of BMGlvA2 on inflammatory response genes in the intestinal epithelium}

As shown in Fig. 4, ETEC challenge significantly elevated the expression levels of inflammatory response genes

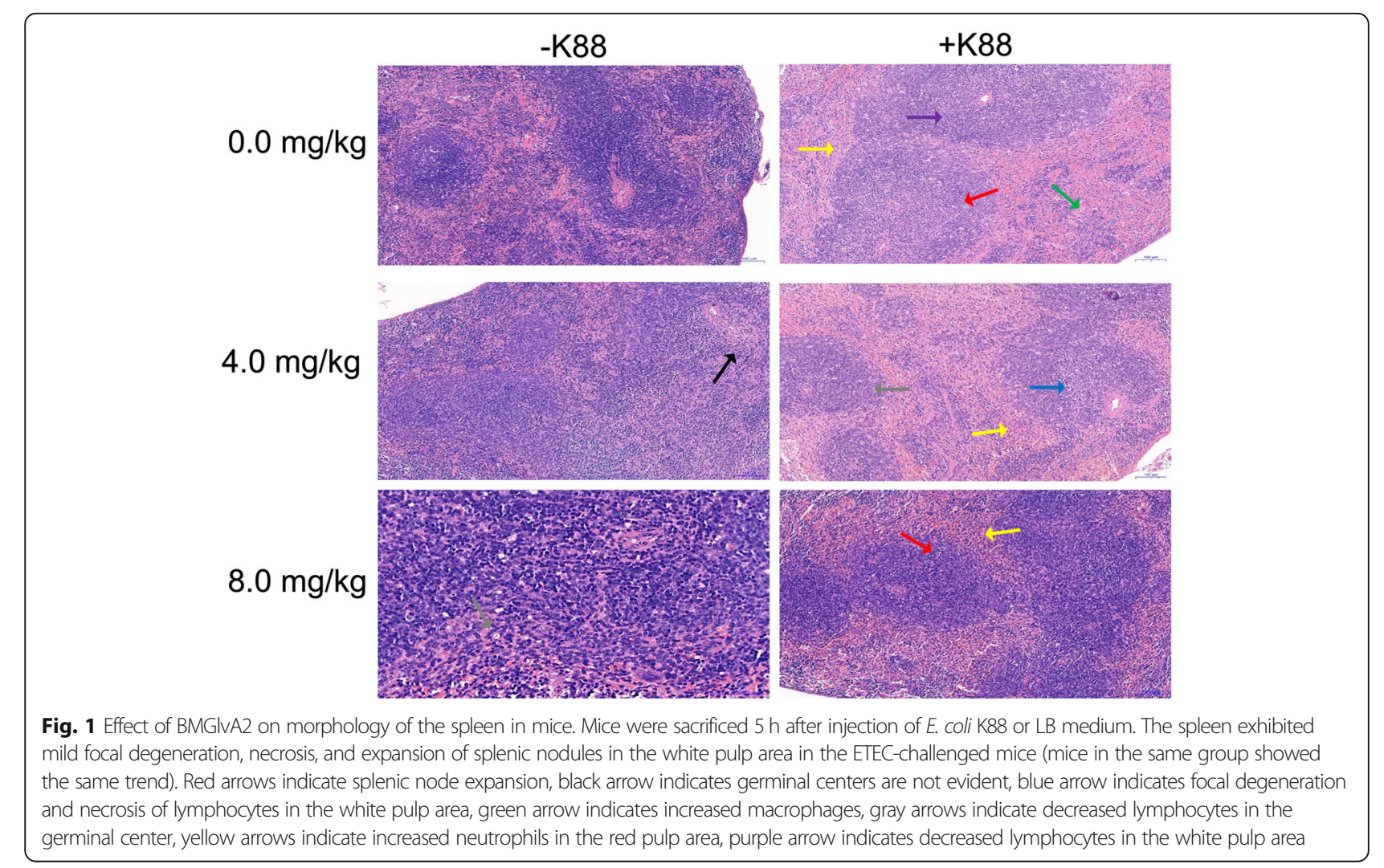


Table 2 Effect of BMGlvA2 on inflammatory cytokines and metabolic indicators in serum

\begin{tabular}{|c|c|c|c|c|c|c|c|c|c|}
\hline \multirow[t]{2}{*}{ Indicators } & \multicolumn{3}{|l|}{$-K 88$} & \multicolumn{3}{|l|}{$+K 88$} & \multicolumn{3}{|l|}{$P$ value } \\
\hline & $0.0 \mathrm{mg} / \mathrm{kg}$ & $4.0 \mathrm{mg} / \mathrm{kg}$ & $8.0 \mathrm{mg} / \mathrm{kg}$ & $0.0 \mathrm{mg} / \mathrm{kg}$ & $4.0 \mathrm{mg} / \mathrm{kg}$ & $8.0 \mathrm{mg} / \mathrm{kg}$ & Interaction & K88 & A \\
\hline $\mathrm{IL}-1 \beta \mathrm{ng} / \mathrm{mL}$ & $219.90 \pm 0.01$ & $220.10 \pm 0.02$ & $220.10 \pm 0.03$ & $220.00 \pm 0.04$ & $220.10 \pm 0.03$ & $220.00 \pm 0.02$ & 0.261 & 0.847 & 0.371 \\
\hline IL-6 ng/mL & $9.14 \pm 0.1027^{b}$ & $9.47 \pm 0.14^{b}$ & $9.06 \pm 0.08^{b}$ & $79.25 \pm 4.88^{a}$ & $28.52 \pm 5.10^{b}$ & $9.54 \pm 0.09^{b}$ & $<0.0001$ & $<0.0001$ & $<0.0001$ \\
\hline TNFa ng/mL & $215.60 \pm 0.07^{b}$ & $215.90 \pm 0.16^{b}$ & $215.70 \pm 0.08^{b}$ & $230.50 \pm 1.68^{\mathrm{a}}$ & $218.10 \pm 0.70^{b}$ & $215.80 \pm 0.10^{b}$ & $<0.0001$ & $<0.001$ & $<0.001$ \\
\hline D-LA $\mu \mathrm{g} / \mathrm{L}$ & $3.27 \pm 0.00$ & $3.28 \pm 0.01$ & $3.23 \pm 0.03$ & $3.32 \pm 0.00$ & $3.29 \pm 0.01$ & $3.28 \pm 0.01$ & 0.261 & 0.847 & 0.371 \\
\hline CRP mg/L & $4.32 \pm 0.17^{\mathrm{ab}}$ & $3.93 \pm 0.23^{b}$ & $2.67 \pm 0.09^{b}$ & $4.70 \pm 0.38^{\mathrm{ab}}$ & $6.06 \pm 0.55^{\mathrm{a}}$ & $4.70 \pm 0.25^{a b}$ & 0.373 & 0.010 & 0.138 \\
\hline TP g/L & $60.50 \pm 0.61^{a}$ & $58.83 \pm 0.23^{a}$ & $55.52 \pm 0.24^{a b}$ & $52.50 \pm 0.73^{b}$ & $55.87 \pm 0.62^{a b}$ & $57.43 \pm 0.46^{a b}$ & 0.003 & 0.008 & 0.721 \\
\hline GLO g/L & $28.47 \pm 0.35^{a}$ & $27.67 \pm 0.17^{a}$ & $27.10 \pm 0.29^{a b}$ & $24.82 \pm 0.45^{b}$ & $25.88 \pm 0.39^{b}$ & $27.45 \pm 0.29^{a}$ & 0.069 & 0.018 & 0.724 \\
\hline ALB g/L & $32.03 \pm 0.28^{a}$ & $31.27 \pm 0.10^{\mathrm{a}}$ & $29.52 \pm 0.25^{a b}$ & $27.68 \pm 0.31^{b}$ & $29.98 \pm 0.27^{\mathrm{ab}}$ & $29.98 \pm 0.22^{a b}$ & 0.001 & 0.001 & 0.296 \\
\hline$A / G$ & $1.13 \pm 0.01^{\mathrm{ab}}$ & $1.13 \pm 0.01^{\mathrm{ab}}$ & $1.09 \pm 0.01^{b}$ & $1.12 \pm 0.012^{\mathrm{ab}}$ & $1.16 \pm 0.01^{\mathrm{a}}$ & $1.09 \pm 0.01^{b}$ & 0.654 & 0.681 & 0.076 \\
\hline UREA mmol/L & $8.07 \pm 0.11^{b}$ & $7.81 \pm 0.12$ & $7.45 \pm 0.07^{b}$ & $26.24 \pm 1.66^{\mathrm{a}}$ & $7.10 \pm 0.09^{b}$ & $8.99 \pm 0.07^{b}$ & $<0.0001$ & 0.0004 & $<0.000$ \\
\hline CREA $\mu \mathrm{mol} / \mathrm{L}$ & $6.00 \pm 0.23^{b}$ & $6.48 \pm 0.19^{a b}$ & $7.09 \pm 0.19^{a b}$ & $26.25 \pm 2.76^{a}$ & $6.65 \pm 0.13^{\mathrm{ab}}$ & $7.08 \pm 0.21^{\mathrm{ab}}$ & 0.182 & 0.113 & 0.519 \\
\hline ALT U/L & $39.83 \pm 1.63^{\mathrm{a}}$ & $24.40 \pm 0.41^{c}$ & $18.60 \pm 1.85^{c}$ & $36.33 \pm 2.91^{\mathrm{ab}}$ & $27.17 \pm 0.99^{b c}$ & $24.60 \pm 0.39^{c}$ & 0.510 & 0.609 & 0.001 \\
\hline AST U/L & $303.50 \pm 25.74^{\mathrm{a}}$ & $147.00 \pm 6.33^{b}$ & $174.30 \pm 18.02^{b}$ & $325.00 \pm 26.54^{a}$ & $131.80 \pm 7.45^{b}$ & $249.70 \pm 20.66^{\mathrm{ab}}$ & 0.596 & 0.466 & 0.002 \\
\hline
\end{tabular}

The data were expressed as mean \pm SEM. Data with different superscript letters in a row indicated that the differences between different treatment groups were statistically significant $(p<0.05)$. IL-1 $\beta$ interleukin 1 beta, IL-6 interleukin $6, T N F a$ tumor necrosis factor alpha, $D$-LA d-lactic acid, CRP c-reactive protein, TP total protein, GLO globulin, ALB albumin, A/G albumin/globulin, CREA creatinine, $A L T$ alanine aminotransferase, AST glutinous straw transaminase

such as the IL-1 $\beta$, IL-6, and TNF- $\alpha$ in the intestine $(P<$ $0.05)$. However, BMGlvA2 treatment down-regulated their expression levels in the ETEC-challenged mice $(P<0.05)$. Moreover, ETEC challenge activated the expression of two critical molecules (TLR4 and NF- $\kappa B$ ) related to inflammation signaling pathway. Interestingly, BMGlvA2 treatment at a high dose $(8 \mathrm{mg} / \mathrm{kg})$ significantly decreased their expression levels $(P<0.05)$.

\section{Effect of BMGlvA2 on critical genes related to intestinal barrier functions}

We also investigated the expression profiles of critical genes related to intestinal barrier functions. As shown in Fig. 5, ETEC challenge elevated the expression levels of two critical apoptosis related genes (caspase8 and caspase9), but significantly down-regulated the expression of genes related to epithelial functions

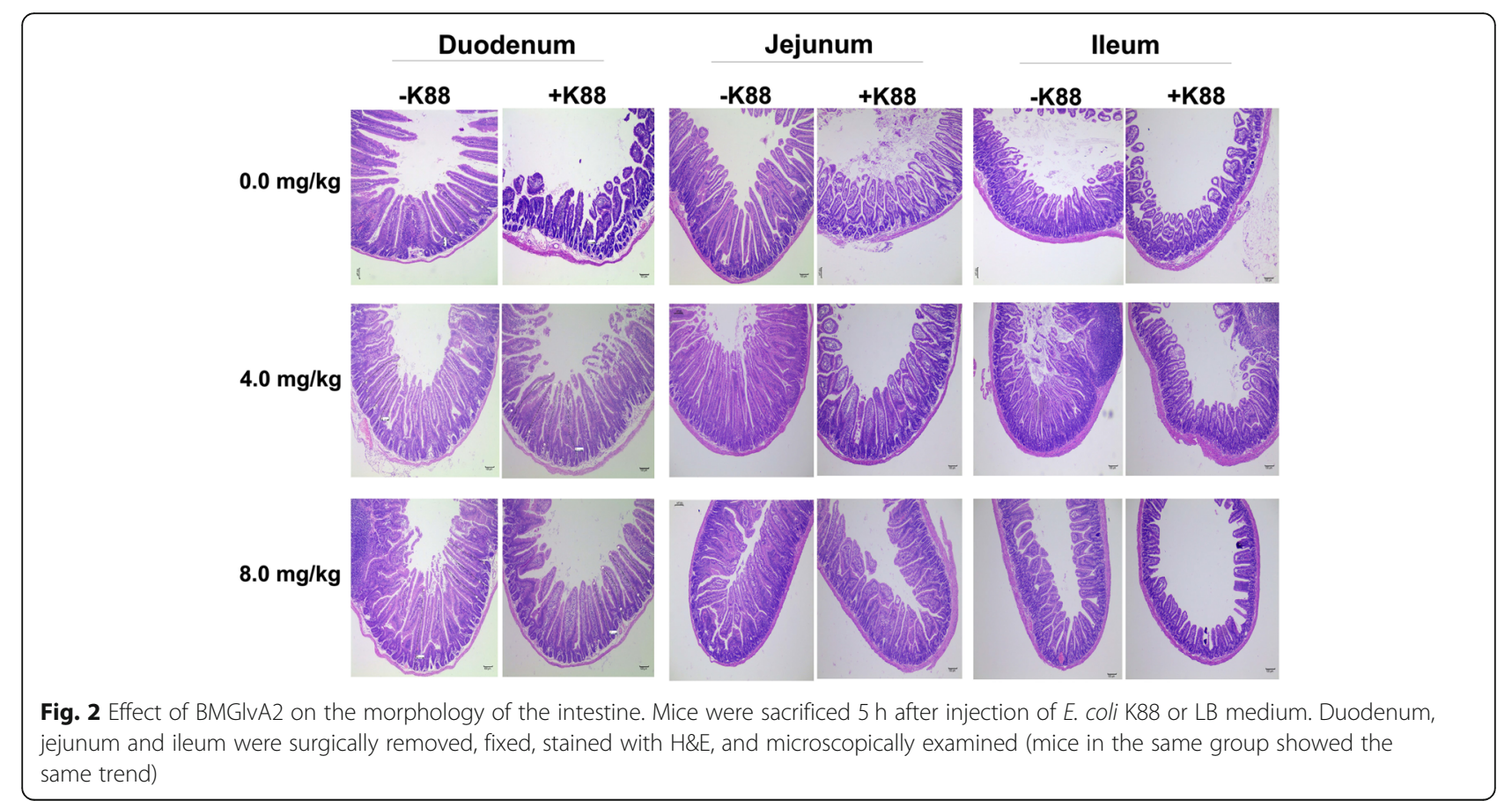




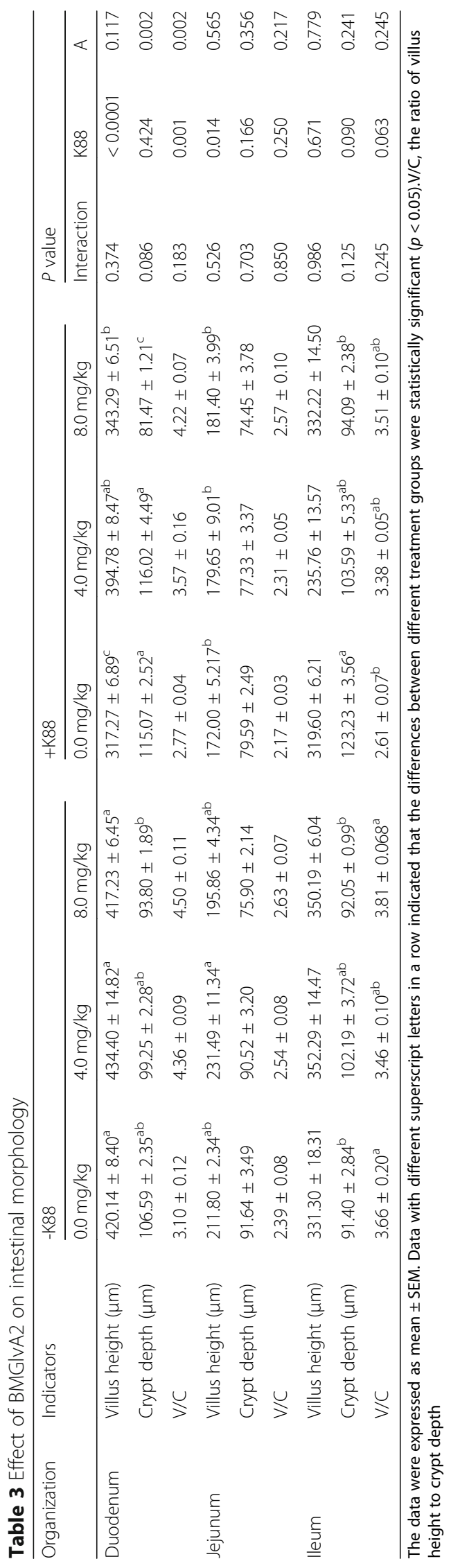




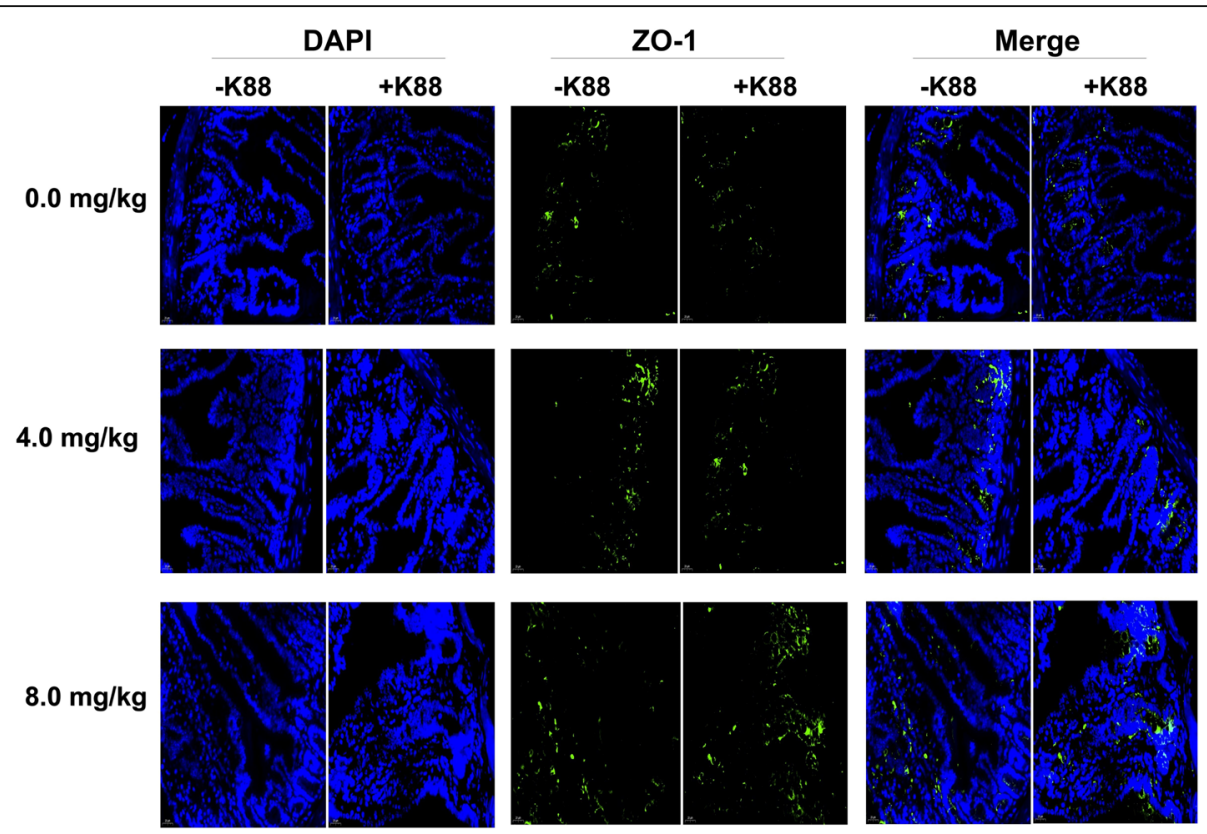

Fig. 3 Effect of BMGlvA2 on distribution and abundance of ZO1 proteins. Representative immunofluorescent images for detection of ZO1 (green) and DAPI (blue). Scale bar $=20 \mu \mathrm{m}$

such as the MUC1, MUC2, SGLT-1, and GLUT-2 $(P<0.05)$. However, BMGlvA2 treatment not only decreased the expression levels of caspase8, but also significantly elevated the expression levels of MUC1, MUC2, and GLUT-2 in the intestine $(P<0.05)$.

\section{Discussion}

In recent years, the AMPs have attracted considerable research interest since they can serve as a substitute for conventionally used antibiotics or serve as a regulator to modulate the immunity [30]. Currently, a wide variety of

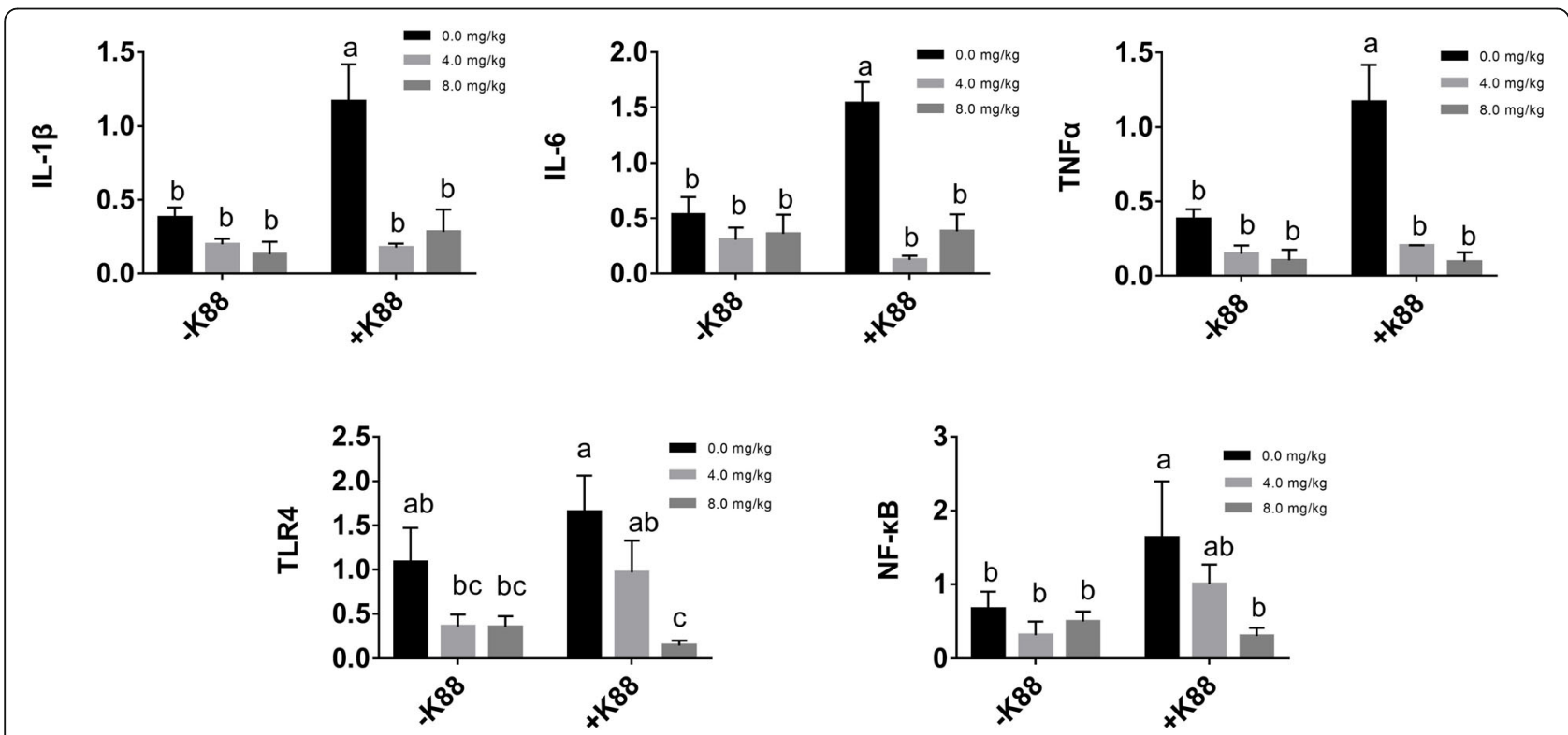

Fig. 4 Effect of BMGlvA2 on the expression of genes related to inflammatory responses. Total RNA was extracted from jejunum tissue and the expression of related genes in jejunum was measured by real-time fluorescence PCR. The target gene mRNA expression level was calculated using the $2^{-\Delta \Delta C t}$ method. ${ }^{a-c}$ Values within a column differ if they do not share a common superscript $(P<0.05)$. IL-1 $\beta$, interleukin 1 beta; IL-6, interleukin 6; TNFa, tumor necrosis factor alpha; TLR4: toll-like receptor 4; NF-KB: nuclear factor-kappa B 

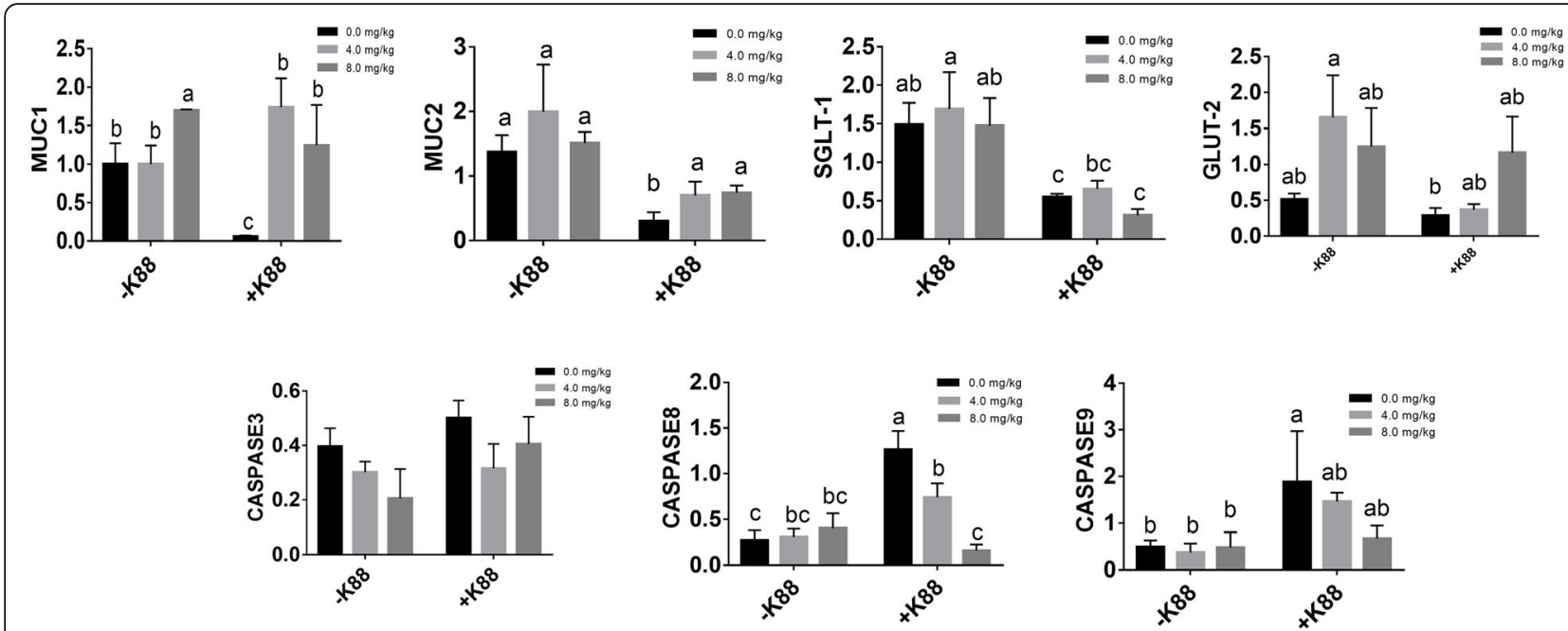

Fig. 5 Effect of BMGlvA2 on the expression of critical genes related to intestinal barrier functions. Total RNA was extracted from jejunum tissue and the expression of related genes in jejunum was measured by real-time fluorescence PCR. The target gene mRNA expression level was calculated using the $2^{-\Delta \Delta C t}$ method. ${ }^{a-c}$ Values within a column differ if they do not share a common superscript $(P<0.05)$. MUC1: Mucin1; MUC2: Mucin2; SGLT-1: Sodium-dependent glucose transporter-1; GLUT-2: Glucose transporter-2; Caspase8, cysteinyl aspartate specific proteinase 8; Caspase9, cysteinyl aspartate specific proteinase 9

forms of AMPs were isolated from mammals (including humans), insects, and amphibians. However, they share common properties such as antibacterial activity, broad spectrum, and nontoxic to mammalian cells [31, 32]. BMGlvA2 is a novel antibacterial peptide isolated from B. mori, which shows antibacterial activity against a broad microbial species [22]. In our previous study, the BMGlvA2 has been successfully expressed in E. coli and we found that the recombinant BMGlvA2 not only had significant antibacterial activities against both the gramnegative and positive bacteria (i.e. ETEC, $S$. aureus, and B. subtilis), but also had no hemolytic activity [27]. In this study, we explored the effect of BMGlvA2 in alleviating ETEC-induced inflammation and intestinal epithelium disruption in mice.

It is a well-known fact that ETEC infection not only induces severe diarrhea in animals, but also impairs a variety of tissues or organs [33]. The spleen is the largest lymphoid organ in the human body and plays a critical role in immune system functions [34]. In this study, ETEC challenge increased the fecal score (marking of the diarrhea) and impaired the spleen tissues. Moreover, the elevated serum concentrations of urea and crea indicated disruption of the kidney function in mice upon ETEC challenge $[35,36]$. The elevated serum concentrations of IL- 6 and TNF- $\alpha$ indicating an acute inflammatory response in mice upon ETEC challenge. These results indicated success of model construction. Interestingly, BMGlvA2 treatment significantly decreased the serum concentrations of IL-6 and TNF- $\alpha$ in ETEC-challenged mice, which suggested that the BMGlvA2 may act as a negative regulator for inflammatory responses. This result is consistent with previous studies on AMPs by using a variety of animal species [37-41]. It's a fact that villi are critical components of the intestinal tract and their geometry provides an indicator of the absorptive capacity of the small intestine [42]. Villus height, crypt depth and the ratio of villus height to crypt depth $(\mathrm{V} / \mathrm{C})$ are common metrics for assessment of intestinal morphology [43]. The intestinal morphology can reveal some information on gut health. A shortening of the villus and deeper crypts may decrease the surface area of the intestinal tract for nutrient uptake. Studies of Gislason et al. and Swidsinski et al. found that the toxins produced by ETEC were closely related to the morphological changes of small intestine [44, 45]. In this study, ETEC challenge significantly decreased the villus height in the duodenum and jejunum, and decreased the $\mathrm{V} / \mathrm{C}$ in the ileum. These results are similar to some previous studies ETEC challenge decreased the villus height and the V/C of the intestine [46-48]. However, BMGlvA2 treatment attenuated the ETEC-induced mucosa lesion. The tight junctions (TJs), which are composed of cytoplasmic scaffold proteins such as ZO-1, claudins, and attachment adhesion molecules, play a critical role in maintaining the intestinal permeability $[49,50]$. However, various enteric pathogens can induce permeability defects in the intestinal epithelium by altering the distribution of tight junction proteins $[51,52]$. Previous study indicated that ETEC infection elevated the mRNA and protein levels of tight junction proteins ZO-1 and occludin [53, 54]. In this study, the ZO-1 staining in the jejunum was diffuse with little staining at the intercellular tight junction region in the ETEC-challenged mice, indicating disruption of the TJs upon ETEC infection. However, BMGlvA2 treatment 
attenuated the ETEC-induced TJs disruption by improving the localization and abundance of the $\mathrm{ZO}-1$ proteins. The improved mucosa morphology and tight junction by BMGlvA2 may be attributed to its antibacterial and antiinflammatory activities, since the bacterial endotoxins (i.e. lipopolysaccharides) and inflammatory cytokines (i.e. TNF- $\alpha$ ) are detrimental to the intestinal epithelium and both can induce the mucosa disruption [55-57].

To gain insights into the mechanisms behind the BMGlvA2 modulated intestinal barrier functions, we explored the expression levels of some critical molecules involved in the regulation of inflammatory response and apoptosis. Cytokines are an important part of the body's cellular immune, which play a critical role in the development of lymphocyte and the subsequent functional activities of the peripheral immune compartment [58]. TNF- $\alpha$, IL-1 $\beta$ and IL-6 are important Proinflammatory cytokine that regulate host immunity to a variety of pathogens through immune cell diferentiation, proliferation, and apoptosis [59]. However, excessive production of Proinflammatory cytokine might lead to body and gut damage [60]. As expected, ETEC challenge significantly elevated the expression levels of critical inflammatory response genes such as the IL-1 $\beta$, IL- 6 , and TNF- $\alpha$ in the intestine, which was consistent with the previous reports $[61,62]$. However, their expression levels were significantly down-regulated by BMGlvA2. The TLR4 and NF- $\kappa B$ are two critical signaling molecules involved in inflammation [63]. In this study, high dose BMGlvA2 treatment significantly decreased their expression levels in the intestine, which offers molecular basis for the BMGlvA2 modulated inflammatory responses. The caspase 8 and caspase 9 are two critical molecules responsible for executing cell death during the demolition phase of apoptosis [64]. MUC1 and MUC2 play important roles in maintaining intestinal epithelial barrier function [52]. In this study, BMGlvA2 significantly decreased the expression levels of caspase 8 and caspase 9, but increased the expression levels of genes related to intestinal barrier functions such as the MUC1, MUC2, and GLUT-2 in ETEC-challenged mice, indicating improved integrity of the intestinal epithelium by BMGlvA2.

\section{Conclusions}

In conclusion, the BMGlvA2 attenuates ETEC-induced inflammatory responses and intestinal mucosa atrophy by reducing the secretion of inflammatory cytokines and the improving the morphology and integrity of intestinal epithelium. Our results suggested a novel function of the AMPs, and the anti-bacterial and anti-inflammatory properties of BMGlvA2 may allow it a potential agent to prevent or alleviate the inflammatory bowel diseases.

\section{Supplementary information}

Supplementary information accompanies this paper at https://doi.org/10. 1186/s13756-019-0651-y.

Additional file 1: Figure S1. SDS-PAGE analysis of rBMGIVA2 produced by E. coli Rosetta. Lane 1 pET28a-Rosetta (induced), Lane 2 pET32aBMGlvA2-Rosetta (non-induced), Lane 3-9 pET32a-BMGlvA2-Rosetta (Induction 3, 4, 5, 6, 7, 8, 9 h), M protein markers. Table S1. Primers for realtime PCR

\section{Abbreviations}

A/G: The ratio of albumin to globulin; ALB: Albumin; ALT: Alanine aminotransferase; AMPs: Antimicrobial peptides; AST: Glutinous straw transaminase; BMGIVA2: Bombyx mori gloverin A2; Caspase8: Cysteinyl aspartate specific proteinase 8; Caspase9: Cysteinyl aspartate specific proteinase 9; CREA: Creatinine; CRP: C-reactive protein; D-LA: D-lactic acid; ETEC: Enterotoxigenic Escherichia coli; GLB: Globulin; GLO: Globulin; GLUT2: Glucose transporter-2; H\&E: Hematoxylin and Eosin; ICR: Institute of Cancer Research; IL-1 $\beta$ : Interleukin 1 beta; IL-6: Interleukin 6; LPS: lipopolysaccharides; MUC1: Mucin1; MUC2: Mucin2; NF-kB: Nuclear factor-kappa B; SGLT-

1: Sodium-dependent glucose transporter-1; TLR4: Toll-like receptor 4; TNF-

a: Tumor necrosis factor alpha; TP: Total protein; V/C: The ratio of villus height to crypt depth; ZO-1: Zonula occludens-1

\section{Acknowledgements}

We thank Yaqiang Dai and Xiang Li for their selfless dedication in the animal experiments. We also thank Kunhong Xie for assisting with the BMGlvA2 preparation and purification.

\section{Authors' contributions}

$\mathrm{QL}$ and $\mathrm{JH}$ conceived the study, performed the experiment, performed data analysis, and contributed to drafting the manuscript. QL carried out the animal experiment. GS, AW, DC, BY, ZH, YL, XM, PZ and JY conceived the experiment and proofread the manuscript. All authors read and approved the final manuscript.

\section{Funding}

This work was supported by by the Key Research and Development Program of Sichuan Province (2018NZDZX0005), the Youth Innovation teams of Animal Feed Biotechnology of Sichuan Province (2016TD0028) and Opening fund of Key Laboratory for Innovative Development and Utilization of Forest Plant Germplasm.

\section{Availability of data and materials}

The datasets used and/or analysed during the current study are available from the corresponding author on reasonable request.

\section{Ethics approval and consent to participate}

All experimental procedures and animal care were carried out in compliance with the regulations of the Animal Care Committee of Sichuan Agricultural University (No. 20180701).

\section{Consent for publication}

Not applicable.

\section{Competing interests}

The authors declare that they have no competing interests.

\section{Author details}

${ }^{1}$ Institute of Animal Nutrition, Sichuan Agricultural University, Chengdu, Sichuan 611130, People's Republic of China. ${ }^{2}$ Key Laboratory for Animal Disease-Resistance Nutrition and Feed, Ministry of Agriculture, Chengdu, Sichuan 625014, People's Republic of China. ${ }^{3}$ Guangdong Key Laboratory for Innovative Development and Uilization of Forest Plant Germplasm, South China Agricultural University, Guangzhou 510642, China. 
Received: 7 July 2019 Accepted: 11 November 2019 Published online: 26 November 2019

\section{References}

1. Nagy B, Fekete PZ. Enterotoxigenic Escherichia coli in veterinary medicine. J Med Microbiol. 2005;295(6-7):0-454.

2. Sack RB. Human diarrheal disease caused by enterotoxigenic Escherichia coli. Annu Rev Microbiol. 1975;29(1):333-54.

3. Zhang HH, You JS, Xu YP, Wang XL, Li XY. China Animal Husbandry \& Veterinary Medicine. 2015;42(2):347-351.

4. Schmidt $H$, Secchi A, Wellmann R, Bach A, Böhrer $H$, Gebhard MM, et al. Journal of Surgical Research. 1996;61(2):521-526.

5. Gupta M, Kumar A. Comparison of minimum inhibitory concentration (MIC) value of statin drugs: a systematic review. Anti Infect Agents. 2019;17(1):4-19.

6. Benhamou RI, Pazit S, Herzog IM, Micha F. Di-N-methylation of anti-grampositive aminoglycoside-derived membrane disruptors improves antimicrobial potency and broadens Spectrum to gram-negative Bacteria. Angew Chem. 2015;54(46):13617-21.

7. Govindappa PK, Gautam V, Tripathi SM, Sahni YP, Raghavendra HLS. Effect of Withania somnifera on gentamicin induced renal lesions in rats. Rev Bras. 2019;29(2):234-40.

8. Gupta M, Sharma R, Kumar A. Comparative potential of simvastatin, Rosuvastatin and Fluvastatin against bacterial infection: an in silico and in vitro study. Orient Pharm Exp Med. 2019:1-7.

9. Rana R, Sharma R, Kumar A. Repurposing of Existing Statin drugs for treatment of Microbial Infections: How much Promising. Infect Disord Drug Targets. 2018;19:224-237.

10. Kapoor Y, Sharma R, Kumar A. Repurposing of existing drugs for the bacterial infections: An In silico and In vitro study. Infectious disorders drug targets. 2018:19:1-24.

11. Michael Z. Antimicrobial peptides of multicellular organisms. Nature. 2002; 415(6870):389-395.

12. Yeaman MR, Yount NY. Mechanisms of Antimicrobial Peptide Action and Resistance. Pharmacological Reviews. 2003;55(1):27-55.

13. Galdiero S. Antimicrobial peptides as an opportunity against bacterial diseases. Current Medicinal Chemistry. 2015;22(14):1665-1677.

14. Riadh $H$, Jeannette Ben H, Gérard V, Jean-Marie L, Marie-Christine S, Neffati M, Ismail F. A new antimicrobial peptide isolated from Oudneya africana seeds. Microbiology \& Immunology. 2010;53(12):658-666.

15. Jangra M, Kaur M, Tambat R, Rana R, Maurya SK, Khatri N, Ghafur A, Nandanwar $\mathrm{H}$. Tridecaptin M, a new variant discovered in mud bacterium shows activity against colistin- and extremely drug-resistant Enterobacteriaceae. Antimicrobial Agents and Chemotherapy. 2019;63(6):e00338.

16. Nijnik A, Hancock R. Host defence peptides: antimicrobial and immunomodulatory activity and potential applications for tackling antibiotic-resistant infections. Emerging Health Threats Journal. 2009;2:e1.

17. Afacan NJ, Yeung ATY, Pena OM, Hancock REW: Therapeutic potential of host defense peptides in antibiotic-resistant infections. Current Pharmaceutical Design. 2012;18(6):807-819.

18. Fran Ois N, Kazuhisa I, Akimasa S, Michimasa H, Hiroshi M, Hideoki O, Isao N. A cathelicidin family of human antibacterial peptide LL-37 induces mast cell chemotaxis. Immunology. 2010;106(1):20-26.

19. Manojit M. Medical emergency--challenges and needs of the hour. Journal of the Indian Medical Association. 2006;104(5):219-223.

20. Tomas G. Defensins: antimicrobial peptides of innate immunity. Nature Reviews Immunology. 2003;3(9):710-720.

21. Zanetti M. Cathelicidins, multifunctional peptides of the innate immunity. Journal of leukocyte biology. 2004;75(1):39-48.

22. Axén A, Carlsson A, Engstr MA, Bennich H. Gloverin, an antibacterial protein from the immune hemolymph of Hyalophora pupae. Febs Journal. 2010; 247(2):614-619.

23. Braff MH, Antoanella B, Victor N, Gallo RL. Cutaneous defense mechanisms by antimicrobial peptides. Journal of Investigative Dermatology. 2005;125(1):9-13.

24. Duits LA, Ravensbergen B, Rademaker M, Hiemstra PS, Nibbering PH. Expression of beta-defensin 1 and 2 mRNA by human monocytes, macrophages and dendritic cells. Immunology. 2002;106(4):517-525.

25. Selsted ME, Ouellette AJ. Mammalian defensins in the antimicrobial immune response. Nature immunology. 2005;6(6):551-557.

26. Sawamura D, Goto M, Shibaki A, Akiyama M, Mcmillan JR, Abiko Y, Shimizu $H$. Beta defensin-3 engineered epidermis shows highly protective effect for bacterial infection. Gene Therapy. 2005;12(10):857-861.
27. Su G, Feng $T$, Daiwen $C$, Bing $Y$, Zhiqing $H$, Yuheng $L$, Xiangbing $M$, Ping $Z$, Jie $Y$, Junqiu L. Expression, Purification and Characterization of a Novel Antimicrobial Peptide: Gloverin A2 from Bombyx mori. International Journal of Peptide Research \& Therapeutics. 2018:1-7.

28. Hoff J. Methods of Blood Collection in the Mouse. Lab Animal. 2010;29(10): 47-53.

29. Murano M, Maemura K, Hirata I, Toshina K, Nishikawa T, Hamamoto N, Sasaki S, Saitoh O, Katsu K. Therapeutic effect of intracolonically administered nuclear factor kappa B (p65) antisense oligonucleotide on mouse dextran sulphate sodium (DSS)-induced colitis. Clinical \& Experimental Immunology. 2010;120(1):51-58

30. Xia X, Cheng L, Zhang S, Wang L, Hu J. The role of natural antimicrobial peptides during infection and chronic inflammation. Antonie Van Leeuwenhoek. 2017;111(Suppl 1):1-22.

31. Giacometti A, Cirioni O, Prete MSD, Paggi AM, D'Errico MM, Scalise G. Combination studies between polycationic peptides and clinically used antibiotics against Gram-positive and Gram-negative bacteria. Peptides. 2000;21(8):1155-1160.

32. Giacometti A, Cirioni $O$, Barchiesi F, Prete MSD, Scalise G: Antimicrobial activity of polycationic peptides. Peptides. 1999;20(11):1265-1273.

33. Lee CY, Kim SJ, Park BC, Han JH. Effects of dietary supplementation of bacteriophages against enterotoxigenic Escherichia coli (ETEC) K88 on clinical symptoms of post-weaning pigs challenged with the ETEC pathogen. Journal of Animal Physiology \& Animal Nutrition. 2017;101(1):8895.

34. Albayrak E, Server $\mathrm{S}$. The relationship of spleen stiffness value measured by shear wave elastography with age, gender, and spleen size in healthy volunteers. Journal of Medical Ultrasonics. 2019:1-5.

35. Zhou Y, Du D, Liu S, Zhao M, Yuan Y, Li L, Chen Y, Lu Y, Cheng J, Liu J. Polyacetylene glycoside attenuates ischemic kidney injury by co-inhibiting inflammation, mitochondria dysfunction and lipotoxicity. Life Sciences. 2018 55-64.

36. Huang J, Yao X, Weng G, Qi H, Ye X. Protective effect of curcumin against cyclosporine A-induced rat nephrotoxicity. Molecular Medicine Reports. 2018;17:6038-6044.

37. Patel S, Akhtar N. Antimicrobial peptides (AMPs): The quintessential 'offense and defense' molecules are more than antimicrobials. Biomedecine \& pharmacotherapie. 2017;95:1276-1283.

38. Mookherjee N, Hancock REW. Cationic host defence peptides: Innate immune regulatory peptides as a novel approach for treating infections. Cellular \& Molecular Life Sciences. 2007;64(7-8):922-933.

39. Fang L, Xu Z, Wang G, Ji F, Mei C, Liu J, Wu G. Directed Evolution of an LBP/ CD14 Inhibitory Peptide and Its Anti-Endotoxin Activity. Plos One. 2014;9(7): e101406.

40. Suzuki K, Murakami T, Kuwaharaarai K, Tamura H, Hiramatsu K, Nagaoka I. Human anti-microbial cathelicidin peptide LL-37 suppresses the LPSinduced apoptosis of endothelial cells. International Immunology. 2011; 23(3):185.

41. Bąbolewska E, Brzezińska-Błaszczyk E. Human-derived cathelicidin LL-37 directly activates mast cells to proinflammatory mediator synthesis and migratory response. Cellular Immunology. 2015;293(2):67-73.

42. Caspary WF. Physiology and pathophysiology of intestinal absorption. American Journal of Clinical Nutrition. 1992;55(1 Suppl):299-308.

43. Yulan L, Feng C, Jack O, Xi L, Jacobi SK, Huiling Z, Zhifeng W, Yongqing $H$. Fish oil enhances intestinal integrity and inhibits TLR4 and NOD2 signaling pathways in weaned pigs after LPS challenge. Journal of Nutrition. 2012; 142(11):2017-2024.

44. Gíslason J, lyer S, Hutchens TW, Bo L. Lactoferrin receptors in piglet small intestine: Lactoferrin binding properties, ontogeny, and regional distribution in the gastrointestinal tract $i$. Journal of Nutritional Biochemistry. 1993;4(9): 528-533.

45. Swidsinski A, Ladhoff A, Pernthaler A, Swidsinski S, Loening-Baucke $V$, Ortner M, Weber J, Hoffmann U, Schreiber S, Dietel M. Mucosal flora in inflammatory bowel disease. Gastroenterology. 2002;122(1):44-54

46. Xun W, Shi L, Zhou H, Hou G, Cao T, Zhao C. Effects of curcumin on growth performance, jejunal mucosal membrane integrity, morphology and immune status in weaned piglets challenged with enterotoxigenic Escherichia coli. International Immunopharmacology. 2015:27(1):46-52.

47. Chang-Hoon K, Chul Young L, Seung-Jae H, Sung-Jae K, Byung-Chul P, Insurk J, Jeong-Hee $\mathrm{H}$. Effects of dietary supplementation of lipidencapsulated zinc oxide on colibacillosis, growth and intestinal morphology 
in weaned piglets challenged with enterotoxigenic Escherichia coli. Animal Science Journal. 2015;85(8):805-813.

48. Wan J, Zhang J, Chen D, Yu B, Mao X, Zheng P, Yu J, Huang Z, Luo J, Luo Y. Alginate oligosaccharide alleviates enterotoxigenic Escherichia coli-induced intestinal mucosal disruption in weaned pigs. Food \& function. 2018;9(12): 6401-6413.

49. Dokladny K, Zuhl MN, Moseley PL. Intestinal epithelial barrier function and tight junction proteins with heat and exercise. Journal of Applied Physiology. 2016;120(6):692-701.

50. Wang B, Wu Z, Ji Y, Sun K, Dai Z, Wu G. L-Glutamine enhances tight junction integrity by activating CAMK kinase 2AMP activated protein kinase signaling in intestinal porcine epithelial Cells. journal of Nutrition. 2016;146(3):501-508.

51. Tong LC, Wang Y, Wang ZB, Liu WY, Sun S, Li L, Su DF, Zhang LC. Propionate Ameliorates Dextran Sodium Sulfate-Induced Colitis by Improving Intestinal Barrier Function and Reducing Inflammation and Oxidative Stress. Frontiers in Pharmacology. 2016;7(e970936).

52. Douglas T, Podolsky DK. Trefoil factors: initiators of mucosal healing. Nature Reviews Molecular Cell Biology. 2003;4(9):721-732.

53. Wang L. Effects of Lactobacillus Reuteri LR1 on Tight Junction Proteins Expression in Ipec-1 Cells during Enterotoxigenic Escherichia coli K88 Infection and Its Underlying Mechanisms. Journal of Animal Science. 2017; 95(suppl 4):222-229.

54. Yang GY, Zhu YH, Zhang W, Zhou D, Zhai CC, Wang JF. Influence of orally fed a select mixture of Bacillus probiotics on intestinal T-cell migration in weaned MUC4 resistant pigs following Escherichia coli challenge. Veterinary Research. 2016:47(1):71-78.

55. Yang L, Liu G, Lian K, Qiao Y, Zhang B, Zhu X, Luo Y, Shang Y, Gu X-L. Dietary leonurine hydrochloride supplementation attenuates lipopolysaccharide challenge-induced intestinal inflammation and barrier dysfunction by inhibiting the NF-KB/MAPK signaling pathway in broilers. Journal of animal science. 2019;97(4):1679-1692.

56. Xiao YT, Yan WH, Cao Y, Yan JK, Cai W. Neutralization of IL-6 and TNF-a ameliorates intestinal permeability in DSS-induced colitis. Cytokine. 2016;83: 189-192.

57. Bernardino ALF, Myers TA, Xavier A, Atsuhiko H, Philipp MT. Toll-like receptors: insights into their possible role in the pathogenesis of lyme neuroborreliosis. Infection \& Immunity. 2008;76(10):4385-4395.

58. He YW, Malek TR. The structure and function of gamma c-dependent cytokines and receptors: regulation of T lymphocyte development and homeostasis. Critical Reviews in Immunology. 1998;18(6):503-524.

59. Sung Hyen L, Lillehoj HS, Jang SI, Lillehoj EP, Wongi M, Bravo DM. Dietary supplementation of young broiler chickens with Capsicum and turmeric oleoresins increases resistance to necrotic enteritis. Br J Nutr. 2013;110(5): 840-847.

60. McKay D, Baird A. Cytokine regulation of epithelial permeability and ion transport. Gut. 1999;44(2):283-289.

61. Pu J, Chen D, Tian G, He J, Zheng P, Mao X, Yu J, Huang Z, Zhu L, Luo J. Protective Effects of Benzoic Acid, Bacillus Coagulans, and Oregano Oil on Intestinal Injury Caused by Enterotoxigenic Escherichia coli in Weaned Piglets. BioMed research international. 2018;2018.

62. Wan J, Zhang J, Wu G, Chen D, Yu B, Huang Z, Luo Y, Zheng P, Luo J, Mao XJljoms. Amelioration of Enterotoxigenic Escherichia coli-Induced Intestina Barrier Disruption by Low-Molecular-Weight Chitosan in Weaned Pigs is Related to Suppressed Intestinal Inflammation and Apoptosis. 2019;20(14): 3485-3488.

63. Wan J, Zhang J, Chen D, Yu B, Huang Z, Mao X, Zheng P, Yu J, He JJRa: Alginate oligosaccharide enhances intestinal integrity of weaned pigs through altering intestinal inflammatory responses and antioxidant status. 2018;8(24):13482-13492.

64. Lavrik IN, Samsonova MG. The systems biology of signaling pathways. Biophysics. 2016;61(1):78-84.

\section{Publisher's Note}

Springer Nature remains neutral with regard to jurisdictional claims in published maps and institutional affiliations.

Ready to submit your research? Choose BMC and benefit from:

- fast, convenient online submission

- thorough peer review by experienced researchers in your field

- rapid publication on acceptance

- support for research data, including large and complex data types

- gold Open Access which fosters wider collaboration and increased citations

- maximum visibility for your research: over $100 \mathrm{M}$ website views per year

At BMC, research is always in progress.

Learn more biomedcentral.com/submissions 